\title{
Adult Colo-Colic Intussusception Induced By a Lipoma Masquerading As a Sigmoid Polyp on Colonoscopy: A Case Report
}

\author{
Nabi $\mathbf{J}^{1}$, Akhter SMQ ${ }^{2}$, Al-Mamun MA ${ }^{3}$, Jahan $\mathrm{N}^{4}$
}

\begin{abstract}
Intussusception in adults is rare, accounting for only 5\% of all cases of intussusceptions and only $1 \%$ of bowel obstruction. Preoperative diagnosis is often difficult due to non specific symptoms and subacute nature. This case report was a per-operatively diagnosed adult colo-colic intussusception induced by a lipoma which mimicked a sigmoid polyp on colonoscopy. A 40-year-old Bengali woman was admitted with two weeks history of colicky lower abdominal pain. Ultrasound abdomen was unremarkable. Colonoscopy revealed a moderately enlarged sigmoid polyp at $25 \mathrm{~cm}$ from the anal verge. A midline incision laparotomy was performed only to reveal a colo-colic intussusception. The intussusception was reduced and the patient underwent a segmental resection of the involved bowel. Histological evaluation confirmed the diagnosis of lipoma of the colon. The patient however satisfactory recovery and remains well six months after surgery. [J Shaheed Suhrawardy Med Coll, 2013;5(1):72-74]
\end{abstract}

Keywords: Adult intussusception, intussusceptions, colonoscopy, lipoma

Received: February 2013; Revised: March 2013; Accepted: May 2013

\section{Introduction}

The invagination of a segment of the intestine into the lumen of the adjacent segment is called intussusception. The usual direction is from proximal to distal segment. Intussusceptions may not be a rare condition in children, but it is very uncommon in adults and accounts for only $5 \%$ of all reported cases and a cause of bowel obstruction in only $1 \%^{1}$. In $90 \%$ of cases, it is secondarily to an identifiable lesion in the bowel; however $10 \%$ may not have any cause ${ }^{2}$. Lipomas in the intestinal tract are quite rare and usually asymptomatic, although lipomas larger than $2 \mathrm{~cm}$ may be a cause of obstruction in the bowel, leading to intermittent nonspecific abdominal pain, diarrhea or bleeding and sometimes by forming a 'lead point' may precipitate intussusception ${ }^{3}$. Pre-operative diagnosis remains a challenge in most of the cases because of non-specific symptoms and is often confirmed at laparotomy ${ }^{4}$.

Lipomas in the intestines should be surgically resected in order to alleviate the symptoms and histological evaluation is required in order to rule out the existence of malignancy in the mass. This case report a rare per-operatively diagnosed adult colo-colic intussusception induced by a lipoma which mimicked a sigmoid polyp on colonoscopy and review the literature on its management.

\section{Case Report}

A 40-year-old Bengali woman was admitted to the Department of sx at, Shaheed Suhrawardy Medical College and Hospital with two weeks history of lower abdominal pain and partial constipation for 6 days. Before admission, the patient had been hospitalized at the local regional hospital with recurrent abdominal pain and the cause of which had not been established. The pain was colicky, dull in character, gradual and subtle in onset it was localized mainly to the left iliac region. The pain progressed to cramps, usually after taking a meal followed by diffuse bloating of the abdomen. There was no history of hematochezia. The patient did not report any chronic illness apart from hypertension and was on medication for one year. On physical examination, the abdomen was flat

1. Dr. Junaid Nabi, Post-Graduate Trainee, Department of Surgery, Shaheed Suhrawardy Medical College and Hospital, Dhaka

2. Dr. S. M. Quamrul Akhter, Assistant Professor, Department of Surgery, Shaheed Suhrawardy Medical College, Dhaka

3. Dr. Mohammad Abdullah Al Mamun, Assistant Professor, Department of Surgery, Shaheed Suhrawardy Medical College, Dhaka

4. Dr. Nelema Jahan, Registrar, Department of Surgery, Shaheed Suhrawardy Medical College and Hospital, Dhaka

5. Dr. Md. Mamunur Rahman, Junior Consultant, Department of Surgery, Shaheed Suhrawardy Medical College and Hospital, Dhaka

\section{Correspondence}

Dr. S. M. Quamrul Akhter, Assistant Professor, Department of Surgery, Shaheed Suhrawardy Medical College, Sher-E-Bangla Nagar, Dhaka-1207, Bangladesh; Email: qa_sanju@yahoo.com; Cell No.: +8801711059879 
and no mass was palpable. There was, however, mild tendemess present in the left iliac region. The abdomen was tympanitic to percussion and bowel sounds were reduced. Routine blood investigations revealed mild anemia. Ultrasonography of abdomen was unremarkable. Colonoscopy revealed a moderately large sigmoid polyp at $25 \mathrm{~cm}$ from the anal verge (Figure I) rest of the colon was normal. Biopsy from the lesion was inconclusive and Reported mucoid material contaimed tiny fragments of colonic glands. After a thorough pre-operative workup, laparotomy was performed through a midline incision intended to remove the sigmoid polyp. However, on opening the abdomen, a colo-colic intussusception was found. The part of the colon involved was edematous al beit neither gangrenous nor friable. It was reduced by gently 'milking' the intussusceptum proximally. A moderately large, polypoid, intra-luminal mass was pal pated which was attached to the anti-mesentric border by a small stalk. A segmental resection of the involved colon was performed. The viable and non-edematous resection ends were fashioned together. The anterior abdominal wall was closed in layers. The resected specimen showed an intra-luminal polyp as the 'lead point' and it was soft in consistency, yellowish-white in measaring measured $6.8 \times 3.7 \mathrm{~cm}$. Histological evaluation demonstrated fat cells proliferating in the submucosal layer and was confirmed the diagnosis of lipoma of the large intestine. The patient made a satisfactory recovery and was discharged on 9th postoperative day. The patient was reviewed monthly and she remains well 6 months after surgery. A written informed consent was obtained from the patient for publication of this case report and any accompanying image.

\section{Discussion}

Adult intussusception is quite rare In most cases tumor acts a 'lead point' for the intussusception. Such condition could raise the probability of a malignancy in the bowel; however, it has been reported that $52.0-80.0 \%$ of adult intussusception are caused by benign lesions $\mathrm{s}^{1,5}$, including lipomas, inflammatory polyp, hyperplastic polyp and hamartomatous polyps. Among these, lipoma is the most common benign tumor in both small and large bowel intussusceptions ${ }^{5}$. Small lipomas in the colon are usually asymptomatic. Autopsy reports have demonstrated their incidental presence in a large number of cases (ranging from $0.2-0.3 \%$ ). Most of the benign lesions in the large bowel are polypoid-shaped; hence the intussusception commonly develops before the tumor has grown to a size sufficient to cause obstruction of the contents in the intestine ${ }^{6}$. Additionally, preoperative diagnosis is usually difficult due to lack of specific clinical symptoms and examination findings. Imaging modalities such as ultrasonography (US) and computed tomography scan (CT) of the abdomen are valuable in establishing a diagnosis of intussusception and intestinal lipoma7; however, in this case the diagnosis was established peroperatively.

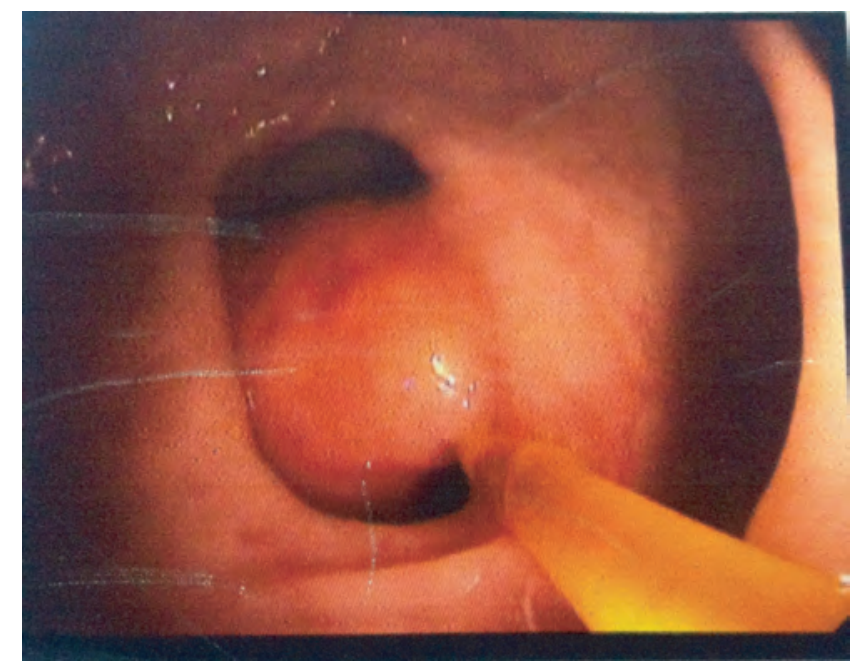

Figure I: Colonoscopy reveal ed a moderatel y large sigmoid polyp at $25 \mathrm{~cm}$ from the anal verge

Broadly, there are two approaches to treatment, like conservative management (reduction with barium or air ${ }^{8}$, followed by close observation) and the surgical intervention. In younger patients with no demonstrable anatomical lead point, conservative management may be suitable. There are reports of patients with conditions such as hemophilia and ulcerative colitis $^{10}$ which have been managed conservatively after resuscitation. Surgical options for intussusception are open surgery and laparoscopic surgery. Laparoscopic surgery for intussusception, even though technically more difficult, is increasing and there are reports of successful reduction of intussusceptions ${ }^{11}$. In resourcelimited settings such as Bangladesh, open surgery is still the preferable choice. Open surgery is al so indicated in large sized lesions $(>7 \mathrm{~cm})$, and in events of strangulation and malignancy. Open surgery is recommended in cases of intussusception in adults (middle aged and older) as become wide surgical resection is possible compared to manipulative reduction ${ }^{12}$. This may reduce the risk of 'manual' tumor spread'. In patients over 60 years of age, primary resection without reduction is advocated. Due to increased risk of mal ignancy.

\section{Conclusion}

Adult colo-colic intussusception is an uncommon presentation and pre-operative diagnosis is often chal lenging which is usually missed or delayed due to nonspecific and subacute symptoms. Lipomas in the gastrointestinal tract are rare lesions and most common complications include obstruction and intussusception when they act as a 'lead point'. For prompt diagnosis, a high index of suspicion and appropriate use of investigations (US, CT and barium enema) is recommended. Surgical intervention is often necessary in adul ts due to frequent association with malignant lesions.

\section{References}

1. Azar T, Berger DL. Adult intussusception. Ann Surg 1997;226(2):134-8 2. Stuhenhord WT, Thorbjarnarson B. Intussusception in adults. Ann Surg 1970;172 (2):306-310 
3. Yao. T Primary small intestinal tumors. Stomach Intestine 2001; 36(7):881- 2001

4. Meshikhes AW, Al-Momen SA, Al Talaq FT, Al-Jaroof AH. Adult intussusception caused by a lipoma in the small bowel: report of a case. Surg Today 2005; 35:161-163

5. Chiang J M, Lin YS. Tumor spectrum of adult intussusception. J Surg Oncol 2008; 98:444-447

6. Wood KF. Ileo-colic intussusception in an adult. Br MedJ 1954; 2:970

7. Urbano J, Serantes A, Hernandez L, Turegano F. Lipomainduced jejunojejunal intussusception: US and CT diagnosis. Abdom Imaging 1996; 21:522-524

8. Yal cin S, Ciftci AO, Karaagaoglu E, Tanyel FC, Senocak ME.
Presenting clinical features and outcome in intussusception. Indian J Pediatr 2009; 76:401-405

9. Howard JM, Hanly AM, Stephens RB. Conservative management resulting in complete resolution of a double intussusception in an adult haemophiliac. Colorectal Dis 2008;10:197-198

10. Maldonado TS, Firoozi B, Stone D, Hiotis K. Colocolonic intussusception of a giant pseudopolyp in a patient with ul cerative colitis: a case report and review of the literature Inflamm Bowel Dis 2004;10:41-44 11. Tsushimi T, Matsui N, Kurazumi $\mathrm{H}$, et al. Laparoscopic resection of an ileal lipoma: report of a case. Surg Today 2006; 36:1007-1010 12. Bahadursingh AM, Robbins PL, Longo WE. Giant submucosal sigmoid colon lipoma. AmJ Surg 2003;186:81-82 